\title{
Ion Segregation in Aqueous Solutions
}

\author{
Hongtao Bian, ${ }^{\dagger, \|}$ Jiebo Li, ${ }^{\dagger}, \|$ Qiang Zhang, Hailong Chen, ${ }^{\dagger}$ Wei Zhuang, ${ }^{*}{ }^{\ddagger}$ Yi Qin Gao, ${ }^{*}, \S$ \\ and Junrong Zheng*, ${ }^{\dagger}$
}

\author{
${ }^{\dagger}$ Department of Chemistry, Rice University, Houston, Texas 77005, United States \\ ${ }^{\ddagger}$ State Key Laboratory of Molecular Reaction Dynamics, Dalian Institute of Chemical Physics, Chinese Academy of Sciences, Dalian \\ 116023, Liaoning, People's Republic of China \\ ${ }^{\S}$ College of Chemistry and Molecular Engineering, Beijing National Laboratory for Molecular Sciences, Peking University, Beijing \\ 100871, China
}

\section{Supporting Information}

ABSTRACT: Microscopic structures and dynamics of aqueous salt solutions were investigated with the ultrafast vibrational energy exchange method and anisotropy measurements. In KSCN aqueous solutions of various concentrations, the rotational time constants of $\mathrm{SCN}^{-}$anions are proportional to the viscosities of the solutions. However, the reorientation dynamics of the water molecules are only slightly affected by the solution viscosity. With the addition of strongly hydrated $\mathrm{F}^{-}$ anions, the rotations of both $\mathrm{SCN}^{-}$anions and water molecules slow down. With the addition of weakly hydrated $\mathrm{I}^{-}$anions, only the rotation of $\mathrm{SCN}^{-}$anions slows down with that of water molecules unaffected. Vibrational energy exchange measurements show that the separation among $\mathrm{SCN}^{-}$anions decreases with the addition of $\mathrm{F}^{-}$and increases with the addition of $\mathrm{I}^{-}$. The series of experiments clearly demonstrate that both structures and dynamics of ion and water are segregated in the strong electrolyte aqueous solutions.

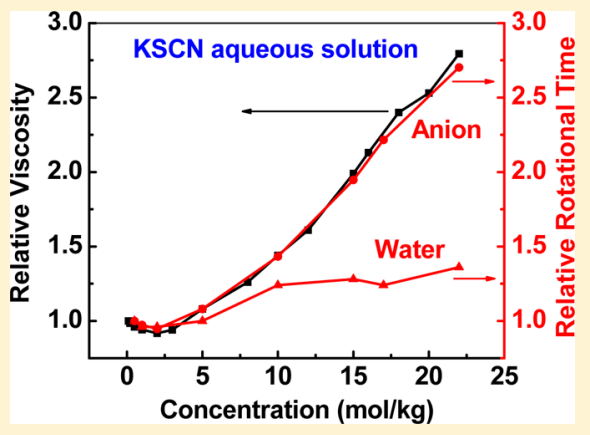

\section{INTRODUCTION}

Many chemical and most biological processes in nature proceed in aqueous electrolyte solutions, ${ }^{1}$ the properties of which have been intensively studied for many years. ${ }^{2-9}$ For very dilute solutions, electrolyte solutions can be well described by the Debye-Huckel theory. ${ }^{10}$ However, this theory begins to fail for quite dilute solutions (even $10^{-3} \mathrm{M}$ solutions with multiplecharged ions). Many practical situations, e.g., fuel cells, batteries, formations of natural mineral compounds, and salt crystallizations, involve much higher concentrations. ${ }^{11}$ As solutions become more concentrated, the attractive forces between unlike ions overcome thermal agitation and condensed assemblies form. The complexity of this assembly process has drawn many research efforts to decipher it, but many open questions concerning the microscopic structures and dynamics of concentrated aqueous solutions remain. ${ }^{2,12-19}$

In the past decades, ultrafast infrared spectroscopy has been frequently used to probe the structures and dynamics of water molecules, ions, and solvent-solute interactions in electrolyte aqueous solutions. ${ }^{20-34}$ Efforts have been focused on the measurements of reorientation, chemical exchange and spectral diffusion dynamics of water molecules in electrolyte aqueous solutions or in confined environments. ${ }^{16,17,35,36}$ These previous studies have revealed many important aspects of water dynamics, e.g., it has been concluded that the presence of interfaces in aqueous solutions can change the dynamics of water molecules on the interfaces. ${ }^{16,17,35,36}$ However, because of the lack of probe for the other component (ions) of the solutions, these studies have not been able to provide knowledge about the structural distribution of ions and the dynamical changes induced by such a distribution in the aqueous solutions.

In this work, by monitoring the anisotropy decays of vibrational excitation signals of both water molecules and anions, we were able to determine the rotational diffusion dynamics of both water molecules and $\mathrm{SCN}^{-}$anions in a series of 1:1 strong electrolyte (KSCN and its mixtures with $\mathrm{KF}, \mathrm{KI}$, $\mathrm{K}_{2} \mathrm{CO}_{3}$ and $\mathrm{K}_{2} \mathrm{HPO}_{4}$ ) aqueous solutions. By monitoring the vibrational energy transfer kinetics ${ }^{30,31,37,38}$ between $\mathrm{SCN}^{-}$and $\mathrm{S}^{13} \mathrm{C}^{15} \mathrm{~N}^{-}$, we were able to determine the relative anion distances in the solutions. We obtained through these experiments clear evidence that both dynamical segregations and ion clusters exist in the unsaturated strong electrolyte aqueous solutions. Our molecular dynamic simulations suggest that the observed dynamical segregations originate from the structural inhomogeneity of the solutions, which is dependent on the relative water affinities of the ions.

\section{EXPERIMENTAL SECTION}

Materials. $\mathrm{KS}^{13} \mathrm{C}^{15} \mathrm{~N}$ was purchased from Cambridge Isotope Laboratory and used without further purification. All other salts were purchased from Sigma-Aldrich and used

Received: October 15, 2012

Revised: November 25, 2012 

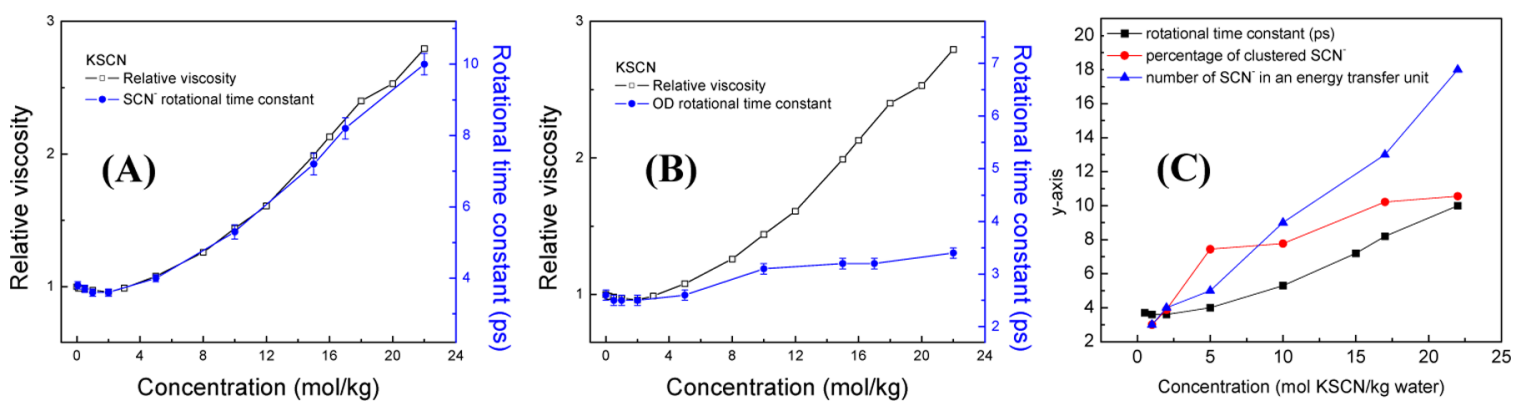

Figure 1. (A) The concentration-dependent viscosities (black) and rotational diffusion time constants of SCN ${ }^{-}$anions (blue) of $\mathrm{KSCN}_{\text {aqueous }}$ solutions. (B) The concentration-dependent viscosities (black) and rotational diffusion time constants of $\mathrm{D}_{2} \mathrm{O}$ (blue) of KSCN aqueous solutions. The unit of concentration is mol (KSCN)/kg (water). (C) The concentration-dependent rotational diffusion time constants of SCN ${ }^{-}$anions (black), percentage of clustered $\mathrm{SCN}^{-}$anions (divided by 9 , red), and number of anions in an vibrational energy transfer unit of an ion cluster (blue, which can be used to represent the fewest number of anions an ion cluster can have) ${ }^{31}$ of KSCN aqueous solutions.

without further purification. $\mathrm{D}_{2} \mathrm{O}$ was from $\mathrm{C} / \mathrm{D} / \mathrm{N}$ Isotopes Inc.

Experimental Methods. The optical setup is described previously. ${ }^{37,39}$ Briefly, a picosecond (ps) amplifier and a femtosecond (fs) amplifier are synchronized with the same seed pulse. The ps amplifier pumps an OPA to produce $\sim 1$ ps MidIR pulses with a bandwidth $10-35 \mathrm{~cm}^{-1}$ in a tunable frequency range from $500 \mathrm{~cm}^{-1}$ to $4000 \mathrm{~cm}^{-1}$ with energy $1-40 \mu \mathrm{J} /$ pulse at $1 \mathrm{kHz}$. The fs amplifier pumps another OPA to produce $\sim 140$ fs Mid-IR pulses with a bandwidth $\sim 200 \mathrm{~cm}^{-1}$ in a tunable frequency range from $600 \mathrm{~cm}^{-1}$ to $4000 \mathrm{~cm}^{-1}$ with energy $1-40 \mu \mathrm{J} /$ pulse at $1 \mathrm{kHz}$. In experiments, the ps IR pulse is the excitation beam. The fs IR pulse is the detection beam of which the frequencies are resolved by a spectrograph yielding the detection axis of a 2D IR spectrum. Scanning the excitation frequency yields the other axis of the spectrum. Two polarizers are inserted into the detection beam path to selectively measure the parallel or perpendicular polarized signal relative to the excitation beam. Vibrational lifetimes are obtained from the rotation-free 1-2 transition signal $P_{\text {life }}=P_{\|}+2 \times P_{\perp}$, where $P_{\|}$ and $P_{\perp}$ are parallel and perpendicular signal respectively. Rotational relaxation times are acquired from the waiting timedependent anisotropy $R=\left(P_{\|}-P_{\perp}\right) /\left(P_{\|}+2 \times P_{\perp}\right)$. Samples were contained in cells composed of two $\mathrm{CaF}_{2}$ windows separated by a Teflon spacer. The thickness of the spacer was adjusted from $0.5 \mu \mathrm{m}$ to $250 \mu \mathrm{m}$ depending upon the optical densities. The experimental optical path and apparatus after the generation of mid-IR pulses were purged with $\mathrm{CO}_{2}$ - and $\mathrm{H}_{2} \mathrm{O}-$ free clean air. All measurements were carried out at room temperature $\left(22{ }^{\circ} \mathrm{C}\right)$. Viscosities were measured with a Cannon-Fenske kinematic viscosity tube.

In water reorientation dynamic measurements, the excitation and detection $\mathrm{OD}$ frequencies were set at the OD central frequency. To avoid the effect of resonance energy transfer on the anisotropy decay, $\mathrm{HOD}$ solutions $\left(1 \mathrm{wt} \% \mathrm{D}_{2} \mathrm{O}\right.$ in $\left.\mathrm{H}_{2} \mathrm{O}\right)$ were used to obtain the $\mathrm{OD}$ reorientation dynamics in the series of $\mathrm{KSCN}$ aqueous solutions. In the neat $\mathrm{D}_{2} \mathrm{O} / \mathrm{H}_{2} \mathrm{O}(1 \mathrm{wt}$ $\%)$ solution, the absorption peak of $\mathrm{OD}$ stretch is centered at around $2505 \mathrm{~cm}^{-1}$. In the $\mathrm{KSCN}$ solutions, with the increase of electrolyte concentration, the central position of OD peak blue shifts. The concentration-dependent Fourier transform infrared (FTIR) spectra are shown in Figure S1. In the analyses of water reorientation dynamics, the heat effect from the OD vibrational relaxation was removed, following the procedure described in our previous publication. ${ }^{30}$ Solutions in $\mathrm{D}_{2} \mathrm{O}$ with various $\mathrm{KS}^{13} \mathrm{C}^{15} \mathrm{~N} / \mathrm{KSCN}(=2 \%)$ concentrations were used to conduct the $\mathrm{SCN}^{-}$rotation anisotropy measurements. The FTIR spectra of KSCN showing the nitrile stretch are displayed in Figure S2 (Supporting Information). The OD and $\mathrm{SCN}^{-}$ anisotropy decay data are displayed in Figure S3 and tabulated in Table S1.

Molecular Dynamics Simulation Method. The widely used SPC/E model was adopted for the calculations of water. The parameters of KSCN, $\mathrm{F}^{-}$, and $\mathrm{I}^{-}$are listed in Table S7. In the calculations, each cubic box was filled with water molecules, and ions which were inserted randomly. The numbers of water molecules and ions in the simulation boxes are listed in Table S8. The geometries of water molecules and $\mathrm{SCN}^{-}$anions were kept rigid. The Lorentz-Berthelot rules were used for the combined LJ parameters. The temperature was weakly coupled to a bath with the Nose-Hoover thermostats at $298 \mathrm{~K}$ with the relaxation time of $0.1 \mathrm{ps}$. The weak coupling Berendsen scheme was used to control the pressure with the coupling time constant of 1 ps. The equations of motion were integrated using the leapfrog algorithm with a time step of $2 \mathrm{fs}$. The longrange Coulombic forces were treated with the Ewald summation method. The nonbonded van der Waals interactions were truncated at $12 \AA$ using the force shifting method. Minimum image conditions were used. For each run, one 5-ns NPT ensemble equilibration was followed by a 10-ns NVE ensemble simulation used to calculate the dynamic properties. Prior to this step, several quenching simulations were carried out in order to reach equilibration for each solution. The simulation trajectories were saved every $100 \mathrm{fs}$. The coordination number for each pair atom was characterized by the geometric criteria $\left(R_{\mathrm{X}-\mathrm{Y}}<3.5 \AA\right.$ for $\mathrm{Ow}-\mathrm{Ow}, \mathrm{Ow}-\mathrm{N}, \mathrm{Ow}-$ $\mathrm{S}, \mathrm{O}-\mathrm{w}-\mathrm{K}, \mathrm{S}-\mathrm{K}$, and $\mathrm{N}-\mathrm{K}$ pairs). All simulations were performed with the Tinker simulation code. ${ }^{40}$

\section{RESULTS AND DISCUSSION}

3.1. Concentration Dependent Rotational Dynamics of $\mathrm{SCN}^{-}$Anions and Water Molecules in KSCN Aqueous Solutions. Figure $1 \mathrm{~A}, \mathrm{~B}$ displays the salt concentrationdependent viscosities (left axis) and rotational diffusion time constants (right axis) of $\mathrm{SCN}^{-}$anions and $\mathrm{D}_{2} \mathrm{O}$ in $\mathrm{KSCN}$ aqueous $\left(\mathrm{D}_{2} \mathrm{O}\right)$ solutions. Below the concentration of $5 \mathrm{~mol}$ $\mathrm{KSCN} / \mathrm{kg}$ water, the viscosity values and rotational time constants of both $\mathrm{SCN}^{-}$and $\mathrm{D}_{2} \mathrm{O}$ are almost unchanged. However, at higher concentrations, the rotational dynamics of anions and water become very different. As the viscosity increases 3-fold, the rotation of anions also slows about 3-fold, but water rotation slows only about $35 \%$. 

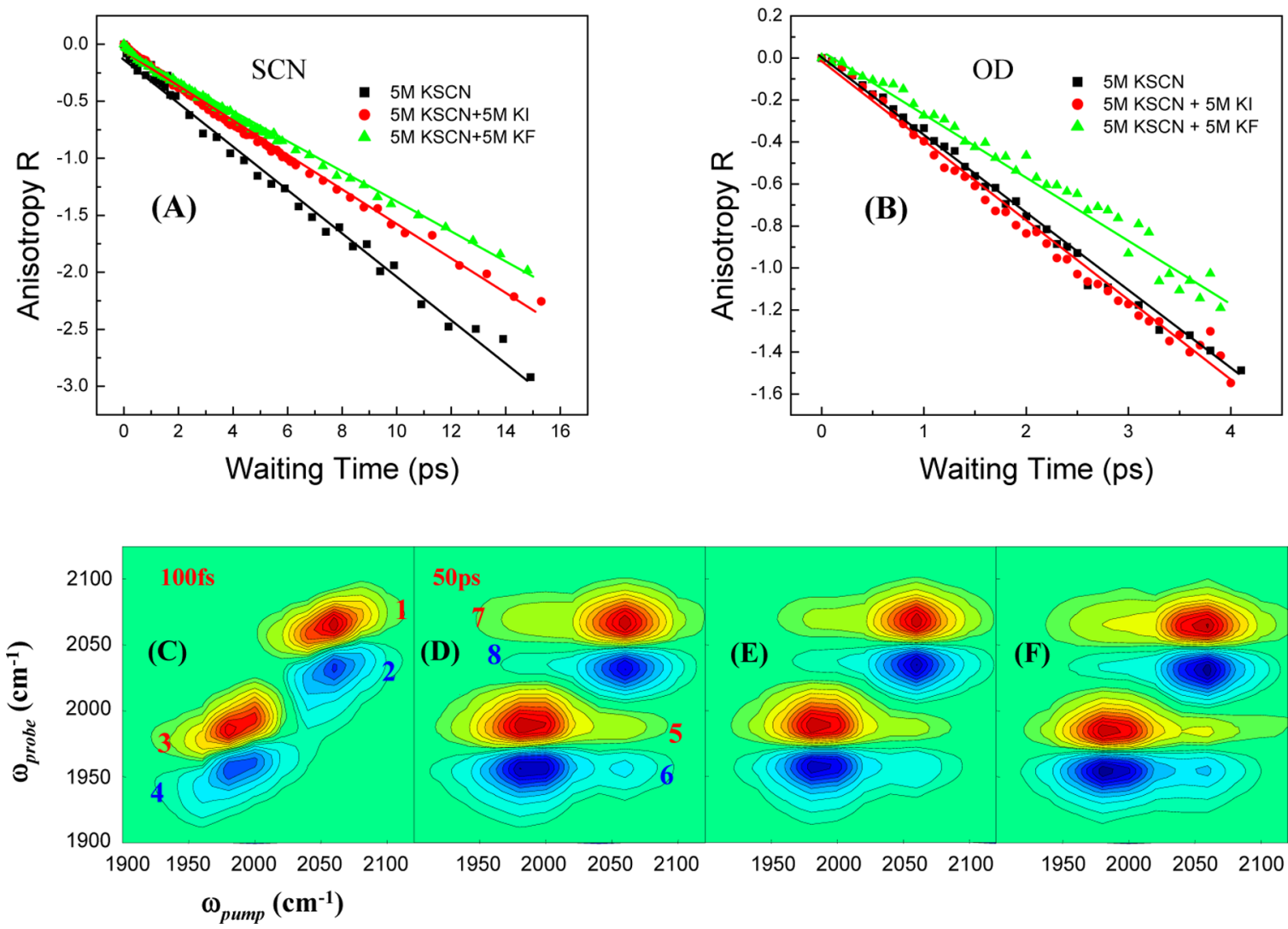

Figure 2. Logarithmic plots of anisotropy $R$ as a function of delay time of a $(5 \mathrm{~mol} \mathrm{KSCN}) / \mathrm{kg}$ aqueous solution, a $(5 \mathrm{~mol} \mathrm{KSCN}+5 \mathrm{~mol} \mathrm{KI}) / \mathrm{kg}$ aqueous solution, and a $(5 \mathrm{~mol} \mathrm{KSCN}+5 \mathrm{~mol} \mathrm{KF}) / \mathrm{kg}$ aqueous solution measured at (A) the $\mathrm{SCN}^{-}$frequency region and (B) the OD frequency region. All the data are fitted to single exponential (solid line). Adding $\mathrm{I}^{-}$into the KSCN solution slows down the rotational dynamics of SCN ${ }^{-}$ anions but not those of the water molecules. Adding $\mathrm{F}^{-}$into the $\mathrm{KSCN}$ solution slows down the rotational dynamics of both $\mathrm{SCN}^{-}$anions and water molecules. (C,D) $2 \mathrm{D}$ IR spectra of the $\left(2.5 \mathrm{~mol} \mathrm{KSCN}+2.5 \mathrm{~mol} \mathrm{KS}{ }^{13} \mathrm{C}^{15} \mathrm{~N}\right) / \mathrm{kg}$ aqueous solution at waiting times of $100 \mathrm{fs}$ and $50 \mathrm{ps}$. (E) $2 \mathrm{D}$ IR spectrum of the $\left(2.5 \mathrm{~mol} \mathrm{KSCN}+2.5 \mathrm{~mol} \mathrm{KS} \mathrm{S}^{13} \mathrm{C}^{15} \mathrm{~N}+5 \mathrm{~mol} \mathrm{KI}\right) / \mathrm{kg}$ aqueous solution at a waiting time of 50 ps. (F) $2 \mathrm{D}$ IR spectrum of the (2.5 mol KSCN $\left.+2.5 \mathrm{~mol} \mathrm{KS}{ }^{13} \mathrm{C}^{15} \mathrm{~N}+5 \mathrm{~mol} \mathrm{KF}\right) / \mathrm{kg}$ aqueous solution at a waiting time of 50 ps. The growth of the cross peaks $5,6,7$, and 8 indicates how fast vibrational energy transfers between $\mathrm{SCN}^{-}$and $\mathrm{S}^{13} \mathrm{C}^{15} \mathrm{~N}^{-}$.

At lower concentrations $(0-2 \mathrm{~mol} / \mathrm{kg})$, the normalized viscosity of the KSCN aqueous solution decreases slightly from 1 (the absolute value of normalized viscosity 1 is 0.97 centistokes) to 0.96 with the increase of $\mathrm{KSCN}$ concentration. This phenomenon has been observed for decades. ${ }^{41}$ Its origin is generally believed to be that both $\mathrm{K}^{+}$and $\mathrm{SCN}^{-}$are weakly hydrated ions, which leads to faster molecular motions, and a negative $\mathrm{B}$ coefficient as defined in the Jones-Dole equation for KSCN aqueous solutions. ${ }^{3,42,43}$ Consistent with this explanation, we observed slightly speeded rotations of both $\mathrm{SCN}^{-}$anions $(3.8 \pm 0.1 \mathrm{ps} \rightarrow 3.6 \pm 0.1 \mathrm{ps})$ and water molecules $(2.6 \pm 0.1 \mathrm{ps} \rightarrow 2.5 \pm 0.1 \mathrm{ps})$ with the increase of concentration from 0 to $2 \mathrm{~mol} / \mathrm{kg}$, as shown in Figure1A,B. In this series of experiments, the determination of individual rotational time has an uncertainty comparable to the change of rotational times. However, the relative difference among the rotational times of samples with different concentrations has a very small uncertainty, which allows us to clearly observe the concentration dependent trend.

At higher concentrations $(>2 \mathrm{~mol} / \mathrm{kg})$, as determined previously $^{31}$ by the vibrational energy transfer method, a substantial fraction of $\mathrm{KSCN}$ ions form ion pairs and clusters. As shown in Figure 1C, as the concentration increases, more and bigger ion clusters form in the solutions. ${ }^{31} \mathrm{SCN}^{-}$ions in bigger ion clusters have a slower angular velocity of rotation event if the velocity on the surface of the cluster remains constant. This effect could be interpreted as an increase of the local viscosity for $\mathrm{SCN}^{-}$anions. Accordingly, the rotation of anions slows down. At the saturation concentration of $\mathrm{KSCN}$, more than $90 \%$ of anions form big clusters. ${ }^{31}$ Indeed, the rotational time constant $(10 \pm 0.3 \mathrm{ps})$ of $\mathrm{SCN}^{-}$anions in the saturated solution approaches that of the anions in the KSCN crystal $(11 \pm 1 \mathrm{ps})$ at the same temperature (data are provided in the Supporting Information, Figure S4). For water molecules, the situation is reversed. At very low ion concentrations where water molecules are the majority, they rotate with the same velocity as bulk water, with a time constant of 2.6 ps. $^{13,20,35}$ With increasing ion concentration, a larger fraction of water molecules interact with the ions. The observed average water reorientational dynamics begin to approach those of the water molecules at the interfaces with the ions and ion clusters. ${ }^{44}$

3.2. $\mathrm{F}^{-}$and $\mathrm{I}^{-}$Have Different Effects on the Dynamics and Structures of KSCN Aqueous Solutions. The ion/ water structural inhomogeneity and dynamic segregations in the KSCN aqueous solutions were also observed in mixed salt aqueous solutions. As displayed in Figure.2A,B (data in red), adding $5 \mathrm{~mol} \mathrm{KI}$ into the $5 \mathrm{~mol} \mathrm{KSCN} / \mathrm{kg}$ aqueous solution slows down the rotational dynamics of the $\mathrm{SCN}^{-}$anions from $4.2 \pm 0.2$ ps to $5.8 \pm 0.3$ ps (Figure $2 \mathrm{~A}$ ). However, the dynamics of water molecules are hardly affected by the addition of KI (Figure 2B), although the overall normalized viscosity of 

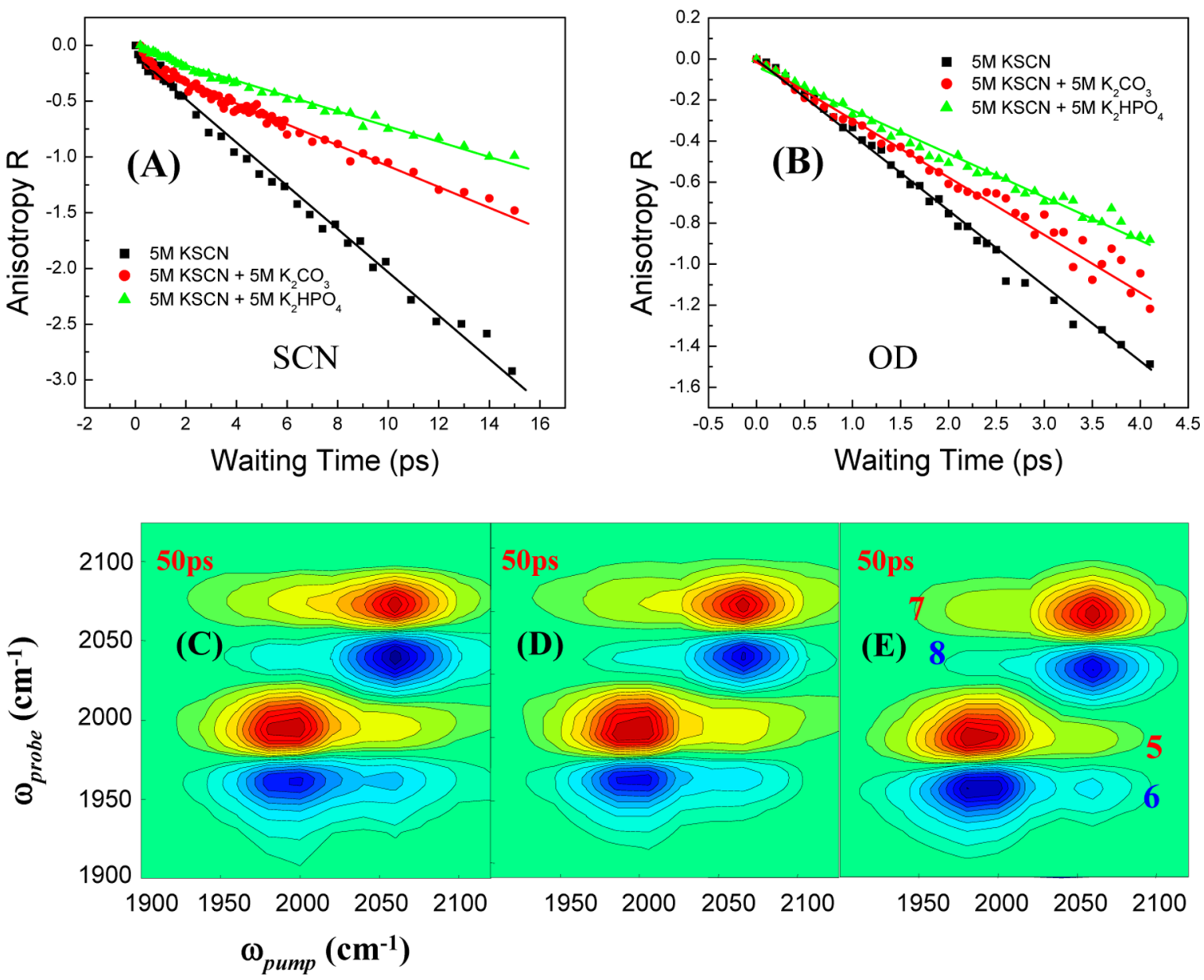

Figure 3. Logarithmic plots of anisotropy $R$ as a function of delay time of a $(5 \mathrm{~mol} \mathrm{KSCN}) / \mathrm{kg}$ aqueous solution, a $\left(5 \mathrm{~mol} \mathrm{KSCN}+5 \mathrm{~mol} \mathrm{~K}_{2} \mathrm{CO} 3\right) / \mathrm{kg}$ aqueous solution, and a $\left(5 \mathrm{~mol} \mathrm{KSCN}+5 \mathrm{~mol} \mathrm{~K}_{2} \mathrm{HPO}_{4}\right) / \mathrm{kg}$ aqueous solution measured at $(\mathrm{A})$ the $\mathrm{SCN}^{-}$frequency region and $(\mathrm{B})$ the $\mathrm{OD}$ frequency region. All the data are fitted to single exponential (solid line). (C) $2 \mathrm{D}$ IR spectrum of the $\left(2.5 \mathrm{~mol} \mathrm{KSCN}+2.5 \mathrm{~mol} \mathrm{KS}{ }^{13} \mathrm{C}^{15} \mathrm{~N}+5 \mathrm{~mol}\right.$ $\left.\mathrm{K}_{2} \mathrm{CO}_{3}\right) / \mathrm{kg}$ aqueous solution at a waiting time 50 ps. (D) $2 \mathrm{D}$ IR spectrum of the $\left(2.5 \mathrm{~mol} \mathrm{KSCN}+2.5 \mathrm{~mol} \mathrm{KS}^{13} \mathrm{C}^{15} \mathrm{~N}+5 \mathrm{~mol} \mathrm{~K} \mathrm{HPO}_{4}\right) / \mathrm{kg}$ aqueous solution at a waiting time 50 ps. (E) $2 \mathrm{D}$ IR spectrum of the $\left(2.5 \mathrm{~mol} \mathrm{KSCN}+2.5 \mathrm{~mol} \mathrm{KS}{ }^{13} \mathrm{C}^{15} \mathrm{~N}\right) / \mathrm{kg}$ aqueous solution at a waiting time of 50 ps (identical to Figure 2D).

the solution increases from $\sim 1.08$ (KSCN solution) to $\sim 1.35$ (KSCN/KI mixed solution). These observations suggest that $\mathrm{I}^{-}$ anions associate with $\mathrm{SCN}^{-}$anions. The likely association of $\mathrm{I}^{-}$ and $\mathrm{SCN}^{-}$was further confirmed by the slowed vibrational energy transfer among the $\mathrm{SCN}^{-}$anions upon the addition of $\mathrm{KI}$ as observed in $2 \mathrm{D}$ IR vibrational energy exchange measurements (Figure 2E). In explanation of Figure 2E, the vibrational energy transfer between $\mathrm{SCN}^{-}$and $\mathrm{S}^{13} \mathrm{C}^{15} \mathrm{~N}^{-}$in the

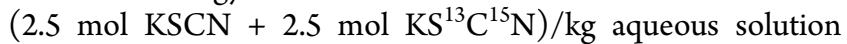
produces cross peaks in the 2D IR spectra (Peaks 5, 6, 7, and 8 in Figure 2D). A smaller cross peak (with fewer contours) indicates a smaller energy transfer rate. Figure 2E,D shows that adding $5 \mathrm{~mol} \mathrm{KI}$ into the potassium thiocyanate solution produces a slightly smaller cross peaks compared to those before the addition, indicative of a slower energy transfer among the thiocyanate anions caused by the addition of KI. The detailed energy transfer kinetics and data analysis for the series of KSCN solutions are provided in the Supporting Information, Figures S6-S12. As elaborated in previous publications, ${ }^{31,38}$ according to the dipole/dipole approximation of which the energy transfer rate is inversely proportional to the sixth power of donor/acceptor distance, ${ }^{45}$ slower energy transfer results from a decrease in the population of thiocyanate anions in close contact (clustered) in the solution, if the transition dipole moments of the energy donor and acceptor and the local refractive index remain constant. Experiments show that the latter two factors change for less than $2 \%$ by the addition of 5 M KI (see Supporting Information Tables S3 and S4). After normalization to take into account the changes in these two factors, the energy transfer rate slows by $10 \% \pm 2 \%$ in Figure 2E. This corresponds to $\sim 10 \%$ concentration decrease of the closely contacted thiocyanate anions or to increased separation between the $\mathrm{SCN}^{-}$ions. These calculations are provided in the Supporting Information, Tables S5 and S6.

In contrast to the results caused by the addition of $\mathrm{KI}$, adding $5 \mathrm{~mol}$ of $\mathrm{KF}$ into the $5 \mathrm{~mol} \mathrm{KSCN} / \mathrm{kg}$ aqueous solution changes the rotational dynamics of both $\mathrm{SCN}^{-}$anions and water molecules. The rotations of both water (from $2.6 \pm 0.1$ ps to $4.0 \pm 0.2 \mathrm{ps}$ ) and $\mathrm{SCN}^{-}$anions (from $4.2 \pm 0.2$ ps to 7.4 $\pm 0.3 \mathrm{ps})$ are slowed down by the addition of $\mathrm{KF}$, as shown in Figure $2 \mathrm{~A}, \mathrm{~B}$ (data in green). It is well-known that, in contrast with $\mathrm{I}^{-}$anions, $\mathrm{F}^{-}$anions are strongly hydrated. ${ }^{46,47}$ The strong binding between $\mathrm{F}^{-}$anions and water molecules slows the rotational dynamics of water as observed, a behavior similar to that observed for other strongly hydrated ions $\left(\mathrm{Li}^{+}, \mathrm{Na}^{+}\right.$, $\mathrm{CO}_{3}{ }^{2-}$, and $\mathrm{SO}_{4}{ }^{2-}$ ) in this and other studies. ${ }^{23}$ Because of its strong water affinity, $\mathrm{F}^{-}$can also out compete the weakly 

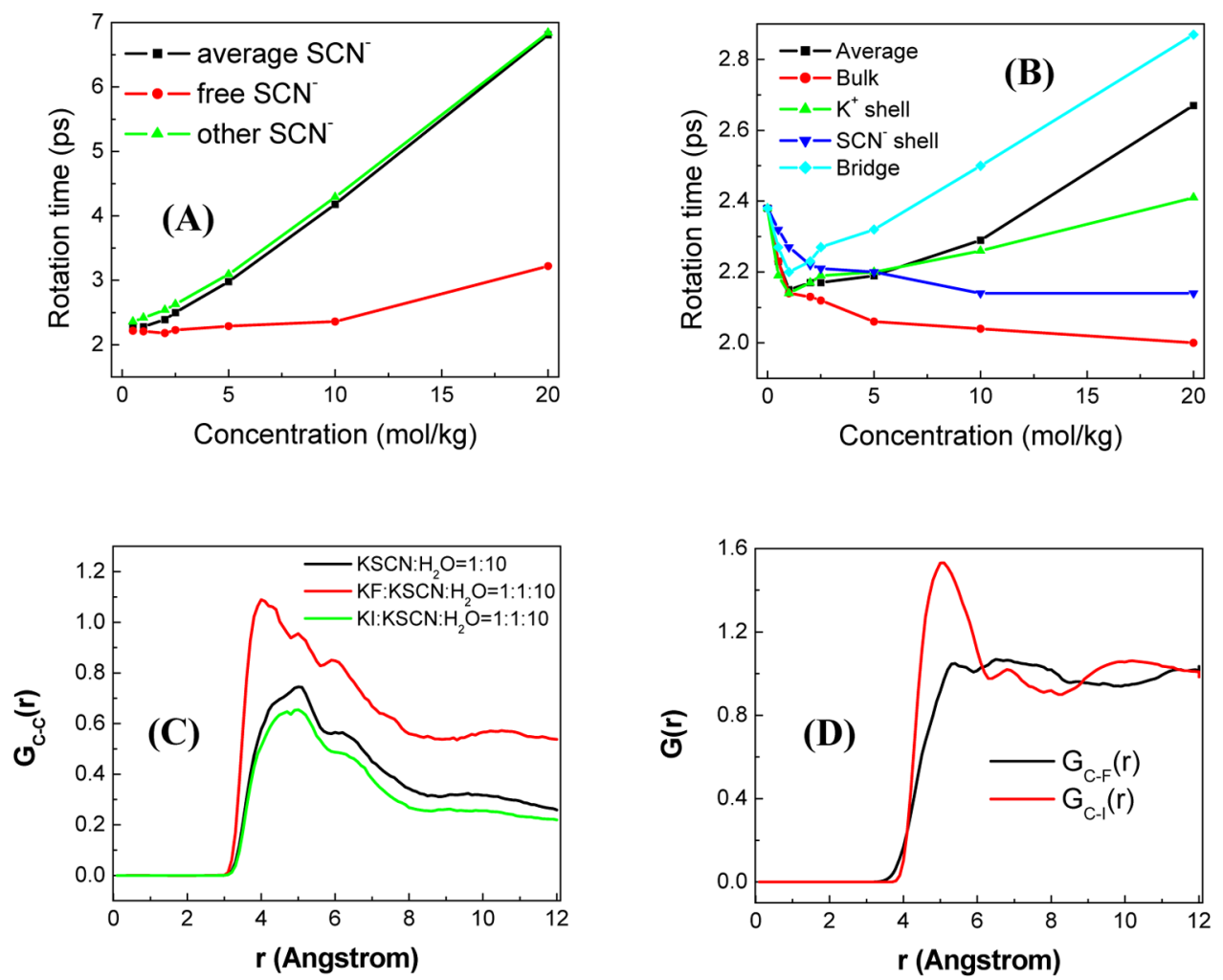

Figure 4. $\mathrm{MD}$ simulation results: (A) The rotational time constants of free $\mathrm{SCN}^{-}$anions of which the first solvation shell contains only water molecules, and other $\mathrm{SCN}^{-}$anions of which the first solvation shell contains at least one ion, and the average $\mathrm{SCN}^{-}$rotational time constants of KSCN solutions at different KSCN concentrations. (B) The rotational time constants of water molecules of different microscopic environments in the KSCN solutions: (1) bulk, of which the first solvation shell is full of water; (2) $\mathrm{K}^{+}$shell, of which the first solvation shell has only one $\mathrm{K}^{+}$cation and water molecules; (3) $\mathrm{SCN}^{-}$shell, of which the first solvation shell has only one $\mathrm{SCN}^{-}$anion and water molecules; (4) bridge, of which the first solvation shell has at least two ions. (C) The C-C RDFs inside the KSCN ion clusters in the $5 \mathrm{~mol} / \mathrm{kg} \mathrm{KSCN}$ aqueous solution, in the $5 \mathrm{~mol} / \mathrm{kg}$ $\mathrm{KSCN}$ aqueous solution added with $5 \mathrm{~mol} \mathrm{KF}$, and in the $5 \mathrm{~mol} / \mathrm{kg} \mathrm{KSCN}$ aqueous solution added with $5 \mathrm{~mol} \mathrm{KI}$. (D) The C-F RDF of the $5 \mathrm{~mol} /$ $\mathrm{kg} \mathrm{KSCN}$ aqueous solution added with $5 \mathrm{~mol} \mathrm{KF}$, and the C-I RDF of the $5 \mathrm{~mol} / \mathrm{kg} \mathrm{KSCN}$ aqueous solution added with $5 \mathrm{~mol} \mathrm{KI}$.

hydrating $\mathrm{SCN}^{-}$for water molecules in the mixed solution in which there are not sufficient water molecules to solvate each ion (the ion/water molar ratio is $1 / 2.5$ ). This will reduce the number of water molecules solvating $\mathrm{SCN}^{-}$anions, resulting in more $\mathrm{SCN}^{-}$clustering in the mixed solution. Both effects contribute to the observed slowing of $\mathrm{SCN}^{-}$rotation. The formation of more and bigger $\mathrm{SCN}^{-}$clusters deduced from the rotational dynamics measurements was further supported by the observed faster vibrational energy exchange among the $\mathrm{SCN}^{-}$anions from the vibrational energy exchange measurements (Figure 2F). The addition of $5 \mathrm{~mol} \mathrm{KF}$ to the $(2.5 \mathrm{~mol}$

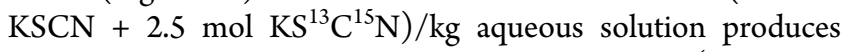
energy exchange cross peaks with higher intensity (about one more contour in peak 6) (Figure 2F), compared to those (Figure 2D) of the solution before the KF addition. The result indicates that the addition of KF facilitates the energy transfer between $\mathrm{SCN}^{-}$and $\mathrm{S}^{13} \mathrm{C}^{15} \mathrm{~N}^{-}$anions, opposite to the effect of the addition of KI.

The experimental results described above qualitatively conclude that in the mixed aqueous solutions, $\mathrm{I}^{-}$anions associate more with $\mathrm{SCN}^{-}$clusters, but $\mathrm{F}^{-}$anions associate more with water molecules. Our MD simulations provide a more quantitative picture about the conclusion. In the KSCN/ KI mixed solution, our MD simulations show that $98 \%$ of the $\mathrm{I}^{-}$ anions have at least one $\mathrm{K}^{+}$in their first solvation shell, and $89 \%$ of these $\mathrm{K}^{+}$cations have at least one $\mathrm{SCN}^{-}$in their first solvation shell. In other words, $87 \%(=98 \% \times 89 \%)$ of the $\mathrm{I}^{-}$ anions are associated to $\mathrm{SCN}^{-}$anions through $\mathrm{K}^{+}$. No $\mathrm{I}^{-}$is found to be in direct contact with $\mathrm{SCN}^{-}$. In the $\mathrm{KSCN} / \mathrm{KF}$ mixed solution, our $\mathrm{MD}$ simulations show that $41 \%$ of the $\mathrm{F}^{-}$ anions have at least one $\mathrm{K}^{+}$in their first solvation shell, and $66 \%$ of these $\mathrm{K}^{+}$cations have at least one $\mathrm{SCN}^{-}$in their first solvation shell. In other words, only $27 \%(=41 \% \times 66 \%)$ of the $\mathrm{F}^{-}$anions are associated to $\mathrm{SCN}^{-}$anions through $\mathrm{K}^{+}$. No $\mathrm{F}^{-}$is found to be in direct contact with $\mathrm{SCN}^{-}$.

3.3. $\mathrm{CO}_{3}{ }^{2-}$ and $\mathrm{HPO}_{4}{ }^{2-}$ Have Similar Effects as $\mathrm{F}^{-}$. The phenomenon that the weakly hydrated $\mathrm{SCN}^{-}$anions are pushed closer to each other by the addition of strongly hydrated $\mathrm{F}^{-}$anions was also observed when other strongly hydrated anions $\left(\mathrm{CO}_{3}{ }^{2-}\right.$ and $\left.\mathrm{HPO}_{4}{ }^{2-}\right)$ were added into the 5 $\mathrm{mol} \mathrm{KSCN} / \mathrm{kg}$ aqueous solution (Figure $3 \mathrm{~A}-\mathrm{E}$ ). Similar to the addition of $\mathrm{KF}$, with the addition of $5 \mathrm{~mol}$ of $\mathrm{K}_{2} \mathrm{CO}_{3}$ into the 5 $\mathrm{mol} \mathrm{KSCN} / \mathrm{kg}$ aqueous solution, the rotations of both $\mathrm{SCN}^{-}$ and water slow down from $4.2 \pm 0.2$ ps to $10.0 \pm 0.3$ ps (Figure $3 \mathrm{~A}$, data in red), and from $2.6 \pm 0.1 \mathrm{ps}$ to $3.8 \pm 0.2 \mathrm{ps}$ (Figure $3 \mathrm{~B}$, data in red), respectively. The addition of $\mathrm{K}_{2} \mathrm{HPO}_{4}$ also slows down the rotations of $\mathrm{SCN}^{-}$and water, from $4.2 \pm 0.2 \mathrm{ps}$ to $13.0 \pm 0.3$ ps (Figure 3A, data in green), and from $2.6 \pm 0.1$ ps to $4.5 \pm 0.2$ ps (Figure 3B, data in green), respectively. The additions of these two anions also produce energy exchange cross peaks with about one more contour (peak 6 in Figure $3 C, D$ ) in 2D IR spectra, compared to those observed (Figure $3 \mathrm{E}$ or Figure 2D) for the pure potassium thiocyanate aqueous solution. These results indicate that the addition of these two 
anions induces faster vibrational energy exchanges among $\mathrm{SCN}^{-}$and $\mathrm{S}^{13} \mathrm{C}^{15} \mathrm{~N}^{-}$. As discussed above, the vibrational energy transfer rate in a solution is determined not only by the energy donor/acceptor distance, but also by the transition dipole moment of the donor and the acceptor, and the local refractive index. Our experiments and calculations show that adding $5 \mathrm{M}$ of these different salts into the $5 \mathrm{M} \mathrm{KSCN} / \mathrm{kg}$-water solution changes the average transition dipole moment of the $\mathrm{CN}$ stretch of $\mathrm{SCN}^{-}$and the average refractive indexes of the solutions by $\leq 2 \%$. Normalized for the small changes of these two factors (details are provided in the Supporting Information), the energy transfer rate changes induced by the salt additions are slowed down $10 \% \pm 2 \%$ by KI, accelerated $14 \% \pm 2 \%$ by $\mathrm{KF}$, accelerated $17 \% \pm 2 \%$ by $\mathrm{K}_{2} \mathrm{CO}_{3}$, and accelerated $7 \% \pm 2 \%$ by $\mathrm{K}_{2} \mathrm{HPO}_{4}$. According to the vibrational energy exchange model, ${ }^{31}$ the normalized energy transfer rate changes correspond to the concentration changes of the direct contact thiocyanate anions: adding $5 \mathrm{M} \mathrm{KI}$ into the $5 \mathrm{M}$ $\mathrm{KSCN} / \mathrm{kg}$-water solution reduced the concentration of energytransfer-efficient (closely contact) thiocyanate anions from $67 \%$ $\pm 2 \%$ to $57 \% \pm 2 \%$. The concentration is increased to $76 \% \pm$ $2 \%$ by the addition of $\mathrm{KF}$, to $71 \% \pm 2 \%$ by the addition of $\mathrm{K}_{2} \mathrm{HPO}_{4}$, and to $79 \% \pm 2 \%$ by the addition of $\mathrm{K}_{2} \mathrm{CO}_{3}$. The small amount of hydroxyl anions produced by the hydrolysis of $\mathrm{F}^{-}, \mathrm{CO}_{3}{ }^{2-}$, or $\mathrm{HPO}_{4}{ }^{2-}$ is not responsible for the effect (faster energy transfer) observed. By contrast, adding $5 \mathrm{~mol} \mathrm{KOD}$ into the thiocyanate solution slows down the energy exchange among the thiocyanate anions, similar to the effect of adding 5 M KI. Data are provided in the Supporting Information (Figure S12 and Table S2).

3.4. Molecular Dynamics Simulations. Molecular dynamics simulations provide further insights into the molecular pictures revealed by the experiments. As shown in Figure $4 \mathrm{~A}, \mathrm{~B}$, the rotations of both $\mathrm{SCN}^{-}$anions and water molecules slow down at high ion concentrations (data in black). Similar to experimental observations, the rotational slowdown of $\mathrm{SCN}^{-}$is much more significant than that of water. The experimentally observed slightly accelerated average rotations of water molecules at $\sim 2 \mathrm{~mol} / \mathrm{kg}$ were reproduced from the $\mathrm{MD}$ simulations, but those of $\mathrm{SCN}^{-}$anions were not. On the other hand, the simulations show that the free $\mathrm{SCN}^{-}$ anions of which the first solvation shell is full of water do rotate a little faster with the increase of concentration in the intermediate concentration range (data in red). The calculations also show that those anions that directly contact with at least one other ion (ion pairs and clusters, green data in Figure $4 \mathrm{~A}$ ) are the major components for the slower rotations at higher concentrations. The water molecules that make the major contribution to the slower rotation are those confined in the ion clusters and pairs (blue data in Figure 4 B), consistent with an earlier simulation study. ${ }^{44}$ For the mixed salt solutions, calculations in Figure 4C show that more $\mathrm{SCN}^{-}$anions are in close contact (with the carbon-carbon distance $<4 \AA$ ) with the addition of $5 \mathrm{~mol} \mathrm{KF}$ into the $5 \mathrm{~mol} / \mathrm{kg} \mathrm{KSCN}$ aqueous solution (the red curve). By contrast, fewer $\mathrm{SCN}^{-}$anions are within this distance range when $\mathrm{KI}$ is added (the blue curve), compared to those of the $5 \mathrm{~mol} / \mathrm{kg} \mathrm{KSCN}$ aqueous solution (the black curve). Because the energy transfer rate is inversely proportional to the sixth power of the donor/acceptor distance under the dipole approximation, these simulation results provide an explanation for the experimentally observed faster vibrational energy transfer rate by adding $\mathrm{KF}$ and the slower energy transfer rate by adding $\mathrm{KI}$. Analyses of the $\mathrm{C}-\mathrm{I}$ and $\mathrm{C}-$
F radial distribution functions (RDF) provide more insights for the interthiocyanate distance change caused by the salt additions. The C-I RDF in Figure 4D (the red curve) has a peak at $\sim 5 \AA$, indicating the direct contact between $\mathrm{SCN}^{-}$and $\mathrm{I}^{-}$(through $\mathrm{K}^{+}$). Such a peak is absent in the $\mathrm{C}-\mathrm{F}$ RDF in Figure $4 \mathrm{D}$ (the black curve), indicating that very few $\mathrm{SCN}^{-}$are in direct contact with $\mathrm{F}^{-}$(through $\mathrm{K}^{+}$) in the mixed $\mathrm{KSCN} / \mathrm{KF}$ aqueous solution. The $\mathrm{MD}$ simulations are in qualitative agreement with the experimental results, strongly supporting the existence of ion segregations in aqueous solutions. Whether the lack of quantitative agreement between experiment and simulation reflects limitations in our simulations awaits further investigation.

\section{CONCLUDING REMARKS}

Combining ultrafast anisotropy measurements, vibrational energy transfer measurements, and molecular dynamics simulations, we were able to observe distinct rotational behaviors of $\mathrm{SCN}^{-}$anions and water molecules in a series of aqueous solutions containing $\mathrm{KSCN}$ and other potassium salts. The dynamical segregation of different components in the solutions reflects the structural inhomogeneity of the solutions. As deduced from the results of vibrational energy transfer measurements and $\mathrm{MD}$ simulations, ions form substantial amounts of ion clusters in the solutions. The structures and concentrations of ion clusters in the KSCN solutions mixed with other potassium salts are dictated by the nature of the added anions: (1) ions with high water affinities, e.g. $\mathrm{F}^{-}$, and $\mathrm{HPO}_{4}{ }^{2-}$, tend to associate with water molecules and therefore reduce the number of water molecules solvating the KSCN ion clusters, promoting the formation of more KSCN ion clusters; and (2) ions with a low water affinity, e.g. $\mathrm{I}^{-}$, tend to associate with the existing KSCN clusters. Because of the ion clustering, the local viscosity of the $\mathrm{SCN}^{-}$anions is different from that of the water molecules, resulting in different rotational dynamics of the two components in the seemingly homogeneous electrolyte aqueous solutions.

\section{ASSOCIATED CONTENT}

\section{S Supporting Information}

Supporting figures and data about FTIR spectra, anisotropy measurements, and data analyses. This material is available free of charge via the Internet at http://pubs.acs.org.

\section{AUTHOR INFORMATION}

\section{Corresponding Author}

*E-mail: junrong@rice.edu (J.Z.); wzhuang@dicp.ac.cn (W.Z.); gaoyq@pku.edu.cn (Y.Q.G.).

\section{Author Contributions}

"These authors contributed equally to the work

\section{Notes}

The authors declare no competing financial interest.

\section{ACKNOWLEDGMENTS}

This material is based upon work supported by the Welch foundation under Award No. C-1752, and the Air Force Office of Scientific Research under AFOSR Award No. FA9550-11-10070. J.R.Z. also thanks the David and Lucile Packard Foundation for a Packard fellowship. W.Z. gratefully acknowledges the support of the NSFC QingNian Grant 21003117, NSFC key Grant 21033008 and Science and Technological Ministry of China Grant 2011YQ09000505. Y.Q.G. thanks the 
NSFC for support (21125311 and 91027044). We also acknowledge Prof. Robert Curl's language modifications and suggestions on the manuscript.

\section{REFERENCES}

(1) Inman, D.; Lovering, D. G. Ionic Liquids; Plenum Press: New York/London, 1981.

(2) Marcus, Y.; Hefter, G. Chem. Rev. 2006, 106, 4585-4621.

(3) Marcus, Y. Chem. Rev. 2009, 109, 1346-1370.

(4) Buchner, R.; Hefter, G. Phys. Chem. Chem. Phys. 2009, 11, 89848999.

(5) Collins, K. D.; Neilson, G. W.; Enderby, J. E. Biophys. Chem. 2007, 128, 95-104.

(6) Collins, K. D. Biophys. Chem. 2006, 119, 271-281.

(7) Cacace, M. G.; Landau, E. M.; Ramsden, J. J. Q. Rev. Biophys. 1997, 30, 241-277.

(8) Jungwirth, P.; Tobias, D. J. J. Phys. Chem. B 2002, 106, 63616373.

(9) Zhang, Y. J.; Cremer, P. S. Curr. Opin. Chem. Biol. 2006, 10, 658663.

(10) Debye, P.; Huckel, E. Phys. Z. 1923, 24, 185-206.

(11) Voigt, W. Pure Appl. Chem. 2011, 83, 1015-1030.

(12) Kropman, M. F.; Bakker, H. J. Science 2001, 291, 2118-2120.

(13) Park, S.; Odelius, M.; Gaffney, K. J. J. Phys. Chem. B 2009, 113, $7825-7835$.

(14) Hassan, S. A. J. Phys. Chem. B 2008, 112, 10573-10584.

(15) Zavitsas, A. A. J. Phys. Chem. B 2001, 105, 7805-7817.

(16) Moilanen, D. E.; Wong, D.; Rosenfeld, D. E.; Fenn, E. E.; Fayer,

M. D. Proc. Natl. Acad. Sci. U.S.A. 2009, 106, 375-380.

(17) Bakker, H. J. Chem. Rev. 2008, 108, 1456-1473.

(18) Laage, D.; Hynes, J. T. J. Phys. Chem. B 2008, 112, 7697-7701.

(19) Lin, Y. S.; Auer, B. M.; Skinner, J. L. J. Chem. Phys. 2009, 131 (144511), 1-13.

(20) Omta, A. W.; Kropman, M. F.; Woutersen, S.; Bakker, H. J. Science 2003, 301, 347-349.

(21) Zheng, J.; Kwak, K.; Asbury, J. B.; Chen, X.; Piletic, I.; Fayer, M. D. Science 2005, 309, 1338-1343.

(22) Ji, M. B.; Odelius, M.; Gaffney, K. J. Science 2010, 328, 10031005

(23) Tielrooij, K. J.; Garcia-Araez, N.; Bonn, M.; Bakker, H. J. Science

2010, 328, 1006-1009.

(24) Owrutsky, J. C.; Raftery, D.; Hochstrasser, R. M. Annu. Rev. Phys. Chem. 1994, 45, 519-555.

(25) Zhong, Q.; Baronavski, A. P.; Owrutsky, J. C. J. Chem. Phys. 2003, 118, 7074-7080.

(26) Sando, G. M.; Dahl, K.; Owrutsky, J. C. J. Phys. Chem. A 2004, 108, 11209-11217.

(27) Hamm, P.; Lim, M.; Hochstrasser, R. M. J. Chem. Phys. 1997, 107, 10523-10531.

(28) Ohta, K.; Tayama, J.; Tominaga, K. Phys. Chem. Chem. Phys. 2012, 14, 10455-10465.

(29) Lenchenkov, V.; She, C. X.; Lian, T. Q. J. Phys. Chem. B 2006, 110, 19990-19997.

(30) Bian, H. T.; Wen, X. W.; Li, J. B.; Zheng, J. R. J. Chem. Phys. 2010, 133 (034505), 1-15.

(31) Bian, H. T.; Wen, X. W.; Li, J. B.; Chen, H. L.; Han, S.; Sun, X. Q.; Song, J.; Zhuang, W.; Zheng, J. R. Proc. Natl. Acad. Sci. U.S.A. 2011, 108, 4737-4742.

(32) Borek, J.; Perakis, F.; Klasi, F.; Garrett-Roe, S.; Hamm, P. J. Chem. Phys. 2012, 136 (224503), 1-7.

(33) Kim, H.; Park, S.; Cho, M. Phys. Chem. Chem. Phys. 2012, 14, 6233-6240.

(34) van der Post, S. T.; Bakker, H. J. Phys. Chem. Chem. Phys. 2012, $14,6280-6288$.

(35) Fayer, M. D.; Moilanen, D. E.; Wong, D.; Rosenfeld, D. E.; Fenn, E. E.; Park, S. Acc. Chem. Res. 2009, 42, 1210-1219.

(36) Fayer, M. D. Acc. Chem. Res. 2012, 45, 3-14.
(37) Bian, H. T.; Li, J. B.; Wen, X. W.; Zheng, J. R. J. Chem. Phys. 2010, 132 (184505), 1-8.

(38) Bian, H. T.; Chen, H. L.; Li, J. B.; Wen, X. W.; Zheng, J. R. J. Phys. Chem. A 2011, 115, 11657-11664.

(39) Chen, H. L.; Bian, H. T.; Li, J. B.; Wen, X. W.; Zheng, J. R. Int. Rev. Phys. Chem. 2012, DOI: 10.1080/0144235X.2012.733116.

(40) Ponder, J. W.; Richards, F. M. J. Comput. Chem. 1987, 8, 10161024.

(41) Mitchell, J. P.; Butler, J. B.; Albright, J. G. J. Sol. Chem. 1992, 21, $1115-1129$.

(42) Jenkins, H. D. B.; Marcus, Y. Chem. Rev. 1995, 95, 2695-2724.

(43) Marcus, Y. J. Chem. Eng. Data 2012, 57, 617-619.

(44) Yang, L. J.; Fan, Y. B.; Gao, Y. Q. J. Phys. Chem. B 2011, 115, 12456-12465.

(45) Woutersen, S.; Bakker, H. J. Nature 1999, 402, 507-509.

(46) Collins, K. D.; Washabaugh, M. W. Q. Rev. Biophys. 1985, 18, $323-422$.

(47) Zhang, Y. J.; Cremer, P. S. Chemistry of Hofmeister Anions and Osmolytes. In Annual Reviews Physical Chemistry; Annual Reviews: Palo Alto, CA, 2010; Vol. 61, pp 63-83. 